\title{
TREINAMENTO INTERNO DE EQUIPE VISANDO O AUMENTO DA LUCRATIVIDADE DA EMPRESA
}

\author{
INTERNAL TRAINING AND COMPANY PROFITS INCREASE
}

\author{
Ana Cláudia Tavares da Silva Manhães * \\ anaclaudia.manhaes@gmail.com \\ * Faculdade Sul Fluminense,Volta Redonda/RJ - Brasil
}

\begin{abstract}
Resumo
Este artigo apresenta um estudo sobre o processo de treinamento interno de equipes proporcionando a lucratividade da empresa. $O$ artigo traz uma análise da relação e importância de ambos para o crescimento organizacional e profissional. A releitura do estudo de caso feito na Eletronorte relata a relação do Treinamento para os Objetivos Estratégicos da Organização. O objetivo é mostrar a importância do processo de Treinamento e Desenvolvimento como vantagem para as empresas alcançarem qualidade de produção, competitividade no mercado, clientes satisfeitos e fidelizados e finalmente aumento significativo dos lucros. A relevância desse trabalho se concerne no fato de que em um ambiente de grande concorrência e que impõe às empresas novos desafios e demandas, o comprometimento e conhecimento dos trabalhadores são exigências que estão como ordem para o sucesso e para a sustentabilidade dos negócios. O resultado mostrou na empresa pesquisada o Impacto do Treinamento no Trabalho (Suporte Gerencial e Social e Suporte Material), para os grupos de treinamento, onde se pode constatar que o treinamento, a capacitação e a motivação beneficiam à gestão de pessoas, mostrando informações importantes a serem consideradas na administração dos Recursos Humanos. Logicamente, esta postura não será alcançada de uma hora para outra nas organizações, cabe aos profissionais de Recursos Humanos e verdadeiros agentes de mudança, fazer desse princípio uma realidade imprescindível para o sucesso das empresas.
\end{abstract}

\section{Palavras-chave:Treinamento; Desenvolvimento; Lucro; Recursos Humanos.}

\begin{abstract}
This article presents a study of the internal training process teams providing the company's profitability. The article presents an analysis of the relationship and importance of both for organizational and professional growth. The case study rereading done in Eletronorte reports regarding training for the Organization's Strategic Objectives. The goal is to show the importance of the process of training and development as an advantage for companies to achieve production quality, market competitiveness, satisfied and loyal customers and ultimately significant increase in profits. The relevance of this work is concerned the fact that in a highly competitive environment and requiring companies new challenges and demands, the workers' commitment and knowledge are requirements that are as order for success and business sustainability. The result showed the company researched the Training Impact at Work (Management and Social and Support Material Support), for training groups where you can see that training, qualification and motivation benefit to people management, showing important information to be considered in the management of Human Resources. Logically, this position will not be achieved from one moment to another in organizations, it is for HR professionals and true agents of change, make
\end{abstract}


this principle a necessary reality for the success of companies.

Keywords: Training; Development; Profit; Human Resources.

\section{1 - INTRODUÇÃO}

Sabe-se que para conseguir o sucesso em qualquer empreendimento, é de suma importância que se os colaboradores conheçam todo funcionamento da empresa e que possam desempenhar suas atividades com qualidade e de forma satisfatória. Com isso, percebe-se que o treinamento é um processo de curto prazo com um importante objetivo.

Treinamento significa "o preparo da pessoa para o cargo" (CHIAVENATO 1999 p.20), já a área de desenvolvimento se aproxima mais da educação que é o preparo da pessoa "da vida, para a vida e pela vida" (CHIAVENATO 1999 p.20), ou seja, treinamento é uma ação de Recursos Humanos, pontual e desenvolvimento é uma ação mais voltada para o futuro do trabalhador dentro da organização. Podem ser treinamento no trabalho, treinamento formal interno, treinamento formal externo, e à distância (LACOMBE, 2002). Treinar é educar, ensinar, é mudar comportamento, é fazer com que as pessoas adquiram novos conhecimentos, novas habilidades, é ensiná-las a mudar de atitude. Treinar, no sentido mais profundo, é ensinar a pensar, a criar e a aprender a aprender.

Observa-se que em muitas situações, alguns colaboradores da empresa, se veem inseguros na realização de determinadas tarefas, provavelmente por não disporem de conhecimento, ou seja, de nenhum tipo de treinamento suficiente para desenvolver suas atividades. Por conseguinte, é importante frisar que a ausência ou deficiência de um programa de treinamento dos colaboradores interfere diretamente na eficácia organizacional. Dessa forma, torna-se estratégico investir no treinamento, pois ele irá promover conhecimento para melhor satisfazer o cliente, e aumentando os lucros da empresa.

Além disso, o treinamento aumenta a produtividade dos colaboradores em seus respectivos cargos, aumentando, consequentemente, a lucratividade da empresa. Logo, fica evidente que oferecer treinamento não é um luxo, mas sim uma grande necessidade.

Segundo Chiavenato (2004) os recursos humanos são o patrimônio fundamental das organizações. A valorização do capital humano, ou seja, das pessoas, representa o sucesso do negócio e o diferencial competitivo das organizações bem-sucedidas. O mundo globalizado e mutável onde as empresas vivem uma economia aberta e sem limites, as organizações precisam estar atentas as inovações e a competição acirrada, faz-se necessário uma preparação contínua aos novos desafios. 
Já para Nascimento Carvalho (1997) os principais objetivos do treinamento e desenvolvimento de pessoal refletem as mudanças econômicas, tecnológicas e sociais do mercado onde a empresa atua, exigindo a efetivação de planos de formação profissional que sejam flexíveis, dinâmicos e atualizados.

No mundo atual, onde cada dia mais empresas ingressam no mercado e empreendedores inovam para obter sucesso, é preciso criar um diferencial competitivo para manter-se no mercado. É preciso buscar constantemente o crescimento dentro de cada organização, conscientizar que o treinamento é vital para o colaborador, pois assim, pode torná-lo mais importante, utilizando o potencial talento de cada um.

Para ter lucro uma empresa precisa ter clientes satisfeitos que comprem seus produtos ou serviços, e divulguem a sua satisfação para as outras pessoas, garantindo assim uma penetração no mercado mais elevada.

O treinamento é um processo que auxilia o empregado a adquirir eficiência no seu trabalho presente ou futuro, através de apropriados hábitos de pensamento, ação, habilidades, conhecimentos e atitudes. (CARVALHO; NASCIMENTO, 1997).

Baseado neste fundamento, o objetivo desta pesquisa é compreender a percepção dos colaboradores sobre o treinamento no ambiente de trabalho. Sendo assim, cabe perguntar: Qual a real importância do treinamento para o bom desempenho organizacional visando o lucro?

Diante disso, os objetivos específicos do presente trabalho são:

Identificar ferramentas adequadas para desenvolver colaboradores capazes de atender as demandas da empresa como bom atendimento, resolução de problemas e satisfação do cliente; apontar a importância da capacitação dos colaboradores com condição de atuar na empresa com segurança e conhecimento dos serviços oferecidos de forma a oportunizar o contínuo desenvolvimento pessoal e reconhecer que o treinamento de pessoal leva a uma mudança de atitude criando um clima mais satisfatório entre empregados, aumentando a motivação e a receptividade às técnicas de supervisão e gerência.

Assim, o presente trabalho pretende levantar as principais necessidades de treinamento adequadas a melhoria dos processos de trabalho; Suprir os conhecimentos e as habilidades requeridas para um melhor resultado nos processos de trabalho; Motivar e aumentar o grau de conhecimento dos colaboradores com foco na produtividade da empresa; Entender como o treinamento otimiza processos e resultados organizacionais.

A metodologia deste trabalho foi baseada primeiramente em pesquisa bibliográfica na literatura existente sobre Treinamento. Em um segundo momento, foi realizada uma releitura de um estudo de caso já existente, retirado do artigo intitulado "Relações entre impacto do treinamento no trabalho e estratégia empresarial: o caso da Eletronorte" no Google Acadêmico, do autor Maria Ednei da Silva, Mestre em Administração pela Universidade de Brasília (UnB). Analista de Recursos Humanos Sênior 
da Eletronorte. Para realização da releitura do estudo de caso, fez-se um recorte para posterior análise crítica do caso, utilizando-se para embasamento, a fundamentação teórica do presente artigo.

A pesquisa apresenta uma abordagem qualitativa e como caminho metodológico, pesquisas bibliográficas em artigos disponibilizados na internet sobre o tema Treinamento de Pessoal, bem como livros sobre Administração de Recursos Humanos analisando pressupostos teóricos que levam ao embasamento dos objetivos e justificativa desse estudo.

Este trabalho foi dividido em dois tópicos, não considerada a introdução do material. O tópico 1 aborda conceito de treinamento e desenvolvimento; o tópico 2, por sua vez, sintetiza a importância do treinamento como ferramenta de gestão de pessoas.

\section{2 - CONCEITO DE TREINAMENTO E DESENVOLVIMENTO}

Segundo Barreto (1995), "Educação profissional que visa adaptar o homem ao trabalho em determinada empresa, preparando-o adequadamente para o exercício de um cargo podendo ser aplicado a todos os níveis ou setores da empresa".

Já para Milkovich e Boudreau (2000), treinamento consiste em "Aperfeiçoar as capacidades e motivações dos empregados a fim de torná-los futuros membros valiosos da organização".

Sobre Treinamento e Desenvolvimento existem definições distintas que vão desde diferenciá-los por considerarem treinamento voltado mais para a área técnica e desenvolvimento para a área comportamental. Também são habitualmente definidos a partir da visão de que treinamento é quando se trabalha a manutenção sobre o conhecimento anteriormente adquirido e desenvolvimento, refere-se ao conhecimento que o indivíduo ainda não possui.

O treinamento envolve a transmissão de conhecimentos específicos relativos ao trabalho, atitudes frente aos aspectos da organização, da tarefa e do ambiente, e desenvolvimento de habilidades. Vale lembrar que todo trabalho voluntário não carece menos de treinamento do que funções remuneradas. Não se deve basear somente na disposição e boa vontade das pessoas. O treinamento e desenvolvimento aplicam-se totalmente em diversas situações.

De acordo com Chiavenato (1999),

O treinamento é importante porque possibilita aos colaboradores terem a capacidade de desenvolver suas tarefas com eficácia, reduzindo obstáculo, solucionando problemas com mais rapidez, beneficiando assim a organização como um todo.

O funcionário é uma "peça chave" da empresa, logo, se ele funciona corretamente, a organização também funcionará. A esse respeito, Robbins (2002 p.469) ressalta que: “A maioria dos treinamentos 
visa à atualização e ao aperfeiçoamento das habilidades técnicas dos funcionários”. Percebe-se, então, que o treinamento pode trazer um retorno considerável para o profissional e para organização, pois um profissional bem qualificado terá, consequentemente, uma motivação maior e o seu resultado na execução das tarefas será melhor e mais produtiva, logo, a maior produtividade do empregado poderá contribuir efetivamente para os resultados da empresa. Segundo Milkovich (2000), a solução para obterse um diferencial competitivo, através dos colaboradores é:

Talvez a melhor estratégia de RH seja contratar, treinar e remunerar as pessoas para que elas criem as melhores estratégias futuras, não importa em que condições. Essa estratégia daria menos ênfase na capacidade das pessoas em implementar as estratégias de hoje, e mais ênfase nos traços humanos genéricos, como criatividade, inteligência, curiosidade, confiabilidade e comprometimento com a organização, o que conduziria a estratégia mais eficazes (MILKOVICH e BOUDREAU 2000 p.137).

Então, para obter vantagem, as pessoas precisam estar em primeiro plano, às empresas terão que procurar investir nesse recurso, afinal todo recurso para dar resultado, de alguma forma, deve ser incentivado, não esquecendo que a empresa deve encarar o treinamento como uma fonte de lucratividade permitindo que as pessoas contribuam efetivamente para os resultados do negócio a longo prazo. $\mathrm{O}$ capital intelectual tem capacidade de gerar riqueza, mas para que isso aconteça é preciso que a organização atraia, retenha e desenvolva esse capital da melhor maneira possível. Segundo Marras (2005 p.128), "é necessário que as empresas considerem, principalmente, a importância dos seus ativos intangíveis, como o capital intelectual e as competências profissionais dos seus trabalhadores”. Isso trará uma motivação para o colaborador, fazendo com que o mesmo sempre procure a melhor maneira de realizar suas tarefas e sendo assim, a empresa criará um diferencial competitivo em relação às outras.

Tipos de treinamento e Avalição dos resultados

A abordagem de treinamento dentro de uma organização envolve cinco fases: (1) Levantamento de necessidades, (2) Projeto do programa, (3) Implementação, (4) Avaliação e (5) Monitoração. 


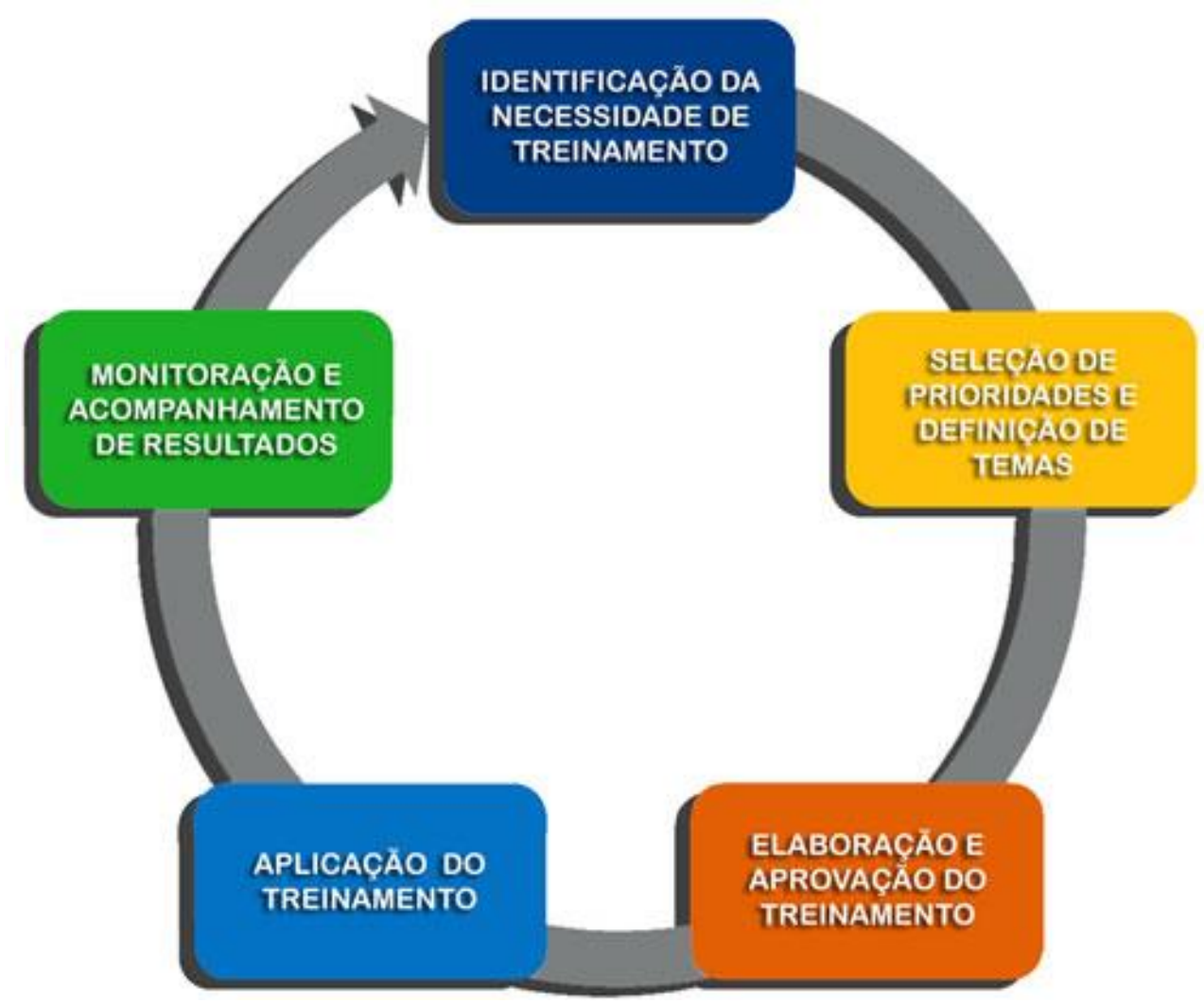

Figura 01: O ciclo do treinamento

Fonte: (Santos, 2016)

\subsection{LEVANTAMENTO DE NECESSIDADES}

Segundo Boog (2001), LNT geralmente é realizado pela equipe de treinamento em todos os departamentos da empresa, seus clientes internos. Por isso é importantíssimo manter todos os canais de comunicação abertos. Escutar os gestores, os líderes, os colaboradores é a principal forma de avaliar onde estão as lacunas - ou onde há a necessidade de treinamento. Observação, Entrevistas e Solicitação das áreas são os 3 principais passos de um Levantamento e necessidades.

\subsection{PROJETO DO PROGRAMA}

Para os autores Tachizawa, Ferreira e Fortuna (2001) com base nos resultados obtidos na fase de análise, planeje o treinamento. Essa fase consiste em identificar os objetivos da organização, que medem o que o funcionário deve ser capaz de fazer após a conclusão do treinamento e a forma como o isso será apresentado. Na fase de planejamento, também pode ser criado esboços para ajudar no desenvolvimento do programa de treinamento. 


\subsection{IMPLEMENTAÇÃO}

Ainda segundo os mesmos autores (2001), implementação é a aplicação e condução do programa de treinamento. Desenvolva um plano para implementar processos e ferramentas na organização. Esse plano descreverá como fazer uma transição eficaz do estado atual da organização para que se adapte às suas metas.

\subsection{AVALIAÇÃO}

É a verificação dos resultados obtidos com o treinamento, isso propicia o feedback necessário ao profissional de RH, Depois de implementar o processo e as ferramentas em um projeto de desenvolvimento, você precisará avaliar o esforço empreendido. As metas estabelecidas foram alcançadas? Avalie o pessoal, o processo e as ferramentas para conhecer as áreas que precisarão de atenção na próxima fase da implementação do processo.

\subsection{MONITORAÇÃO}

E finalmente a última fase, é claro que nenhuma empresa quer ver todo seu trabalho e investimento jogado fora, e para isso é preciso monitorar sempre para que as mudanças alcançadas não se percam na rotina do trabalho.

Deve-se existir uma ligação direta entre os Objetivos estratégicos e os Programas de treinamento. Diferente do que pensam a grande maioria, em muitos dos casos o treinamento e desenvolvimento dos gestores é muito mais importante. Na última década essa necessidade vem crescendo, a medida que as organizações competem nos mercados de sucessos. Por isso, foram criados métodos apropriados para esse tipo de colaboradores/gestores.

Tendo isso em vista a importância do treinamento aos colaboradores e gestores, fica fácil compreender que para qualquer empresa que pretenda obter resultados superiores nesse atual mercado competitivo, o investimento nas pessoas representa um dos caminhos. O primeiro passo é compreender que todo ser humano é dotado de potencial produtivo. O que varia é o grau com que o potencial de cada um é utilizado ou aproveitado. Então, o treinamento bem aplicado trará benefícios para a instituição. Tachizawa, Ferreira e Fortuna (2001) destacam que é necessário levar-se em consideração os diferentes tipos de treinamento: $O$ treinamento de integração que tem como objetivo a adaptação do funcionário à organização; O treinamento técnico-operacional que objetiva a capacitação da pessoa para desempenhar 
as tarefas referentes à sua categoria profissional; O treinamento gerencial o qual visa o desenvolvimento da competência técnica, administrativa e comportamental;

O treinamento comportamental que tem como foco a solução dos conflitos em situações de trabalho. Segundo Marras (2000 p.157), “a execução é a aplicação prática daquilo que foi planejado e programado para suprir as necessidades de aprendizagem detectadas na organização".

Seguido da avaliação, que é a verificação dos resultados obtidos com o treinamento, como qualquer outra ação o treinamento deve ser avaliado para que se determine sua efetividade. Sendo que para cada objetivo, cria-se uma ferramenta especifica de avaliação. São as três formas de avaliação dos programas de treinamento:

Avaliação do Aprendizado: trata-se de verificar o quanto foi proveitoso o processo de ensino e aprendizagem.

Avaliação de reação: objetiva a conhecer a opinião do grupo que recebeu o treinamento.

Avaliação dos resultados do treinamento: visa a averiguação dos resultados do treinamento.

A empresa moderna está deixando para trás o velho pensamento de que treinamento é despesa e não investimento. Ela enxerga treinamentos como um meio para gerar resultados superiores. Quando a empresa investe em treinamento, está investindo nela mesma, no seu próprio crescimento.

A importância do treinamento como ferramenta de gestão de pessoas

"O treinamento pode ser muito importante no resultado da empresa". Entende-se que o treinamento deve incentivar ao funcionário a se autodesenvolver, a buscar o seu próprio meio de reciclagem. (ROBBINS, 2002).

Conscientizar a empresa analisada da importância de reciclar o colaborador, promover educação continuada, preparar profissionais que possam analisar o posicionamento da organização no contexto em que esteja inserida e aprimorar nos colaboradores a capacidade de liderança em relação aos grupos de interesse da organização, também são objetivos específicos estudados.

$\mathrm{O}$ treinamento tem como finalidade melhorar o desenvolvimento profissional do ser humano na sua organização, e no desempenho das suas funções além de ser o processo que visa à preparação e ao aperfeiçoamento das habilidades e dos conhecimentos dos funcionários de uma organização.

A utilização do plano de treinamento bem elaborado é capaz de determinar de forma organizada os rumos do pensamento sistêmico da organização, de forma a capacitar os talentos existentes na organização, maximizando o potencial intelectual da mesma, onde existirão pessoas habilidosas capazes de levar adiante as metas organizacionais estabelecidas. 
Os rendimentos e lucratividade de uma organização estão diretamente ligados a quantidade de treinamentos ao qual seus funcionários são submetidos. Mas esse sucesso não se trata apenas de oferecer o treinamento, e sim de oferecer o treinamento correto. $\mathrm{O}$ que é bom para a empresa $\mathrm{A}$, nem sempre funciona para a B. para isso existe a Abordagem Sistêmica de treinamento, o objetivo do treinamento nada mais é do que contribuir para a realização das metas da empresa. Os diretores e gerentes devem estar atentos as metas estabelecidas para orientar o treinamento de acordo com elas. Nem sempre o que "a concorrência está fazendo" servirá para outra organização, o que resultar em investimento desperdiçado, treinamento mal feito e avaliações inadequadas. O que afeta diretamente o desempenho da empresa.

A empresa moderna está deixando para trás o velho pensamento de que treinamento é despesa e não investimento. Ela enxerga treinamentos como um meio para gerar resultados superiores. Quando a empresa investe em treinamento, está investindo nela mesma, no seu próprio crescimento, segundo Carvalho (2001):

A ênfase do processo de formação profissional é transmitir conhecimento e habilidades tanto em sala de aula como no ambiente de trabalho. Nesse sentido, o treinamento é uma função intrínseca do processo de trabalho e do desenvolvimento da empresa (CARVALHO, 2001 p.12).

O treinamento das empresas possibilita os funcionários a ter uma base do que se vai trabalhar e como trabalhar, aumentando a segurança dos mesmos ao por em prática suas atividades atribuídas, com maior eficiência e eficácia, diminuindo muito a margem de erros e principalmente aumentando a lucratividade da empresa.

\section{3 - ESTUDO DE CASO}

Neste item será apresentado o caminho metodológico deste estudo seguido da caracterização da empresa, assim como, da apresentação do recorte do relato de caso pré-existente, para posterior análise crítica.

\section{1 - CAMINHO METODOLÓGICO}

Um caminho metodológico segundo Cervo et al. (2007 p.27) "é a ordem que se deve impor aos diferentes processos necessários para atingir um certo fim ou um resultado desejado". 
Dessa forma, a metodologia utilizada neste trabalho teórico foi dividida em quatro etapas, onde a primeira consiste em uma pesquisa qualitativa a partir de uma revisão bibliográfica, esta realizada com o objetivo de nivelar os conhecimentos acerca da importância do treinamento para as empresas.

Em um segundo momento, realizou-se um processo de seleção de um Estudo de Caso já existente no banco de dados do Google Acadêmico, cujo critério de seleção consiste na afinidade do estudo com a problemática abordada neste trabalho.

Como terceira etapa buscou-se encontrar um trecho do estudo de caso, cujo assunto abordado pudesse ser utilizado como fonte de pesquisa para realização da análise crítica, elaborada através da releitura de um recorte do estudo apresentado.

A quarta e última etapa deste processo metodológico sustenta-se a partir de Creswell (2007 p.4647) que aponta como um caminho para a pesquisa qualitativa deste trabalho, uma vez que a "literatura é apresentada no final do estudo; ela se torna uma base de comparação e contraste de resultados no estudo qualitativo".

$\mathrm{O}$ autor ainda destaca que esta metodologia se encontra em projetos qualitativos onde torna-se comum o embasamento da teoria com a realidade a partir da comparação entre as teorias apresentadas na fundamentação do estudo com as teorias encontradas no conteúdo analisado.

Caracterização da empresa

O estudo de caso escolhido para releitura trata-se da empresa Eletronorte, é uma concessionária de serviço público de energia elétrica. Essa escolha se deu por conta do seu tamanho e importância, visto que mais de 15 milhões de habitantes da Região Amazônica se beneficiam da energia elétrica gerada pela mesma. A Organização usada nessa pesquisa tem certificação comprovada em excelência empresarial pelas pesquisas e desenvolvimentos que promove.

Após a busca em diversos sites acadêmicos que possuem referência no que se refere à pesquisa de conhecimento, percebe-se a falta de pesquisas científicas, atuais, referentes ao assunto, mesmo com sua importância no mercado atual.

A Centrais Elétricas do Norte do Brasil S.A. - Eletronorte, sociedade anônima de economia mista e subsidiária da Centrais Elétricas Brasileiras S.A. - Eletrobras, é uma concessionária de serviço público de energia elétrica. Criada em 20 de junho de 1973, com sede no Distrito Federal, gera e fornece energia elétrica aos nove estados da Amazônia Legal - Acre, Amapá, Amazonas, Maranhão, Mato Grosso, Pará, Rondônia, Roraima e Tocantins. Por meio do Sistema Interligado Nacional - SIN, também fornece energia a compradores das demais regiões do País.

Dos 25.478.352 milhões de habitantes que vivem na Região Amazônica, segundo Censo 2010 do IBGE, mais de 15 milhões se beneficiam da energia elétrica gerada pela Eletrobras Eletronorte em suas 
quatro hidrelétricas - Tucuruí (PA), a maior usina genuinamente brasileira e a quarta do mundo, Coaracy Nunes (AP), Samuel (RO) e Curuá-Una (PA) - e em parques termelétricos. A potência total instalada é de 9.294,33 megawatts e os sistemas de transmissão contam com mais de 9.888,02 quilômetros de linhas.

\section{2 - RELATO DO CASO}

O presente estudo foi retirado banco de dados do Google Acadêmico, através de um Estudo de Caso intitulado de Relações entre impacto do treinamento no trabalho e estratégia empresarial: o caso da Eletronorte, desenvolvido por Maria Ednei da Silva (2004). A partir desse estudo fez-se o recorte das páginas 14 e 15 apresentado a seguir.

"Na análise da variável Relevância do Treinamento para os Objetivos Estratégicos da Organização, encontrou-se que a maioria dos gestores pesquisados avalia os treinamentos na categoria essencial (compreendendo os pontos 6,5 e 4 ) na escala do instrumento. Na categoria irrelevante, (compreendendo aos pontos 1, 2 e 3), observou-se que houve um número menor de avaliações. Isso significa que os gestores consideraram a maioria dos treinamentos relevantes para os objetivos estratégicos da organização, em maior ou menor grau.

A Tabela 1 apresenta a avaliação dos gestores conforme a escala original do instrumento, referente aos treinamentos do grupo A, e a Tabela 2, a mesma avaliação para os do grupo B.

\section{Tabela 1: Freqüências da Variável Relevância do Treinamento para os Objetivos Estratégicos da Eletronorte na Escala Original (Grupo A)}

\begin{tabular}{|c|c|c|c|c|c|c|}
\hline \multirow{2}{*}{ Treinamento } & \multicolumn{6}{|c|}{ FREQUUÊNCLA RELATIVA NA ESCALA ORIGINAL } \\
\hline & 1 & 2 & 3 & 4 & 5 & 6 \\
\hline R/3 SIN- Sistema Integrado de Gestão & - & - & - & - & $27,3 \%$ & $72,7 \%$ \\
\hline Preparação para a banca PNQ & - & - & $3 \%$ & $27,3 \%$ & $42,4 \%$ & $27,3 \%$ \\
\hline Preparação para a banca PQGF & $3 \%$ & - & $9,1 \%$ & $39,4 \%$ & $36,4 \%$ & $12,1 \%$ \\
\hline ISO 14000 - Auditor Ambiental & - & $3 \%$ & - & $24,2 \%$ & $36,4 \%$ & $36,4 \%$ \\
\hline TPM - Manutenção Produtiva Total & - & - & - & $6,1 \%$ & $36,4 \%$ & $57,6 \%$ \\
\hline MBA - Gestão Empresarial & - & - & $9,1 \%$ & $24,2 \%$ & $36,4 \%$ & $30,3 \%$ \\
\hline Regras de Mercado & - & - & $6,1 \%$ & $9,1 \%$ & $21,2 \%$ & $63,6 \%$ \\
\hline $\begin{array}{l}\text { Planos de Contingências e Emergências } \\
\text { Ambientais }\end{array}$ & - & - & $3 \%$ & $39,4 \%$ & $33,3 \%$ & $24,2 \%$ \\
\hline $\begin{array}{l}\text { Custos Marginais e Tarifação de Energia } \\
\text { Elétrica }\end{array}$ & - & $3 \%$ & $\begin{array}{r}12,1 \\
\%\end{array}$ & $9,1 \%$ & $30,3 \%$ & $45,5 \%$ \\
\hline $\begin{array}{l}\text { Seminário Internacional de Transmissấo } \\
\text { de Energia Elétrica }\end{array}$ & $3 \%$ & $9,1 \%$ & $6,1 \%$ & $39,4 \%$ & $21,2 \%$ & $21,2 \%$ \\
\hline $\begin{array}{l}\text { Estratégia de Negociação e Conflitos } \\
\text { Ambientais }\end{array}$ & - & $6,1 \%$ & $9,1 \%$ & $27,3 \%$ & $36,4 \%$ & $21,2 \%$ \\
\hline
\end{tabular}


Tabela 2: Freqüências da Variável Relevância do Treinamento para os Objetivos Estratégicos da Eletronorte na Escala Original (Grupo B)

\begin{tabular}{|c|c|c|c|c|c|c|}
\hline \multirow{2}{*}{ TrEINAMENTo } & \multicolumn{6}{|c|}{ FREQÜENCIA RELATIVA NA ESCALA ORIGINAL } \\
\hline & 1 & 2 & 3 & 4 & 5 & 6 \\
\hline $\begin{array}{l}\text { ACS - Atualização de Chefes e } \\
\text { Supervisores }\end{array}$ & - & $3 \%$ & $12,1 \%$ & $24,2 \%$ & $36,4 \%$ & $24,2 \%$ \\
\hline MBA - Auditoria & $3 \%$ & $9,1 \%$ & $18,2 \%$ & $42,4 \%$ & $27,3 \%$ & - \\
\hline MBA - Meio Ambiente & - & $6,1 \%$ & $9,1 \%$ & $30,3 \%$ & $36,4 \%$ & $18,2 \%$ \\
\hline $\begin{array}{l}\text { MBA - Gestấo de Pessoas por } \\
\text { Competências }\end{array}$ & - & $6,3 \%$ & $3,1 \%$ & $28,1 \%$ & $34,4 \%$ & $28,1 \%$ \\
\hline $\begin{array}{l}\text { Preposto (Representação Jurídica da } \\
\text { Empresa) }\end{array}$ & $6,1 \%$ & $6,1 \%$ & $33,3 \%$ & $24,2 \%$ & $18,2 \%$ & $12,1 \%$ \\
\hline Anatem (Informática) & $3,2 \%$ & $3,2 \%$ & $19,4 \%$ & $35,5 \%$ & $25,8 \%$ & $12,9 \%$ \\
\hline Inglês & $3 \%$ & - & $21,2 \%$ & $45,5 \%$ & $24,2 \%$ & $6,1 \%$ \\
\hline Informática (Word, Windows etc.) & - & $6,1 \%$ & $18,2 \%$ & $27,3 \%$ & $15,2 \%$ & $33,3 \%$ \\
\hline Primeiros Socorros & - & $6,3 \%$ & $28,1 \%$ & $34,4 \%$ & $15,6 \%$ & $15,6 \%$ \\
\hline $\begin{array}{l}\text { Projeto Bem-Viver (Ikebana, Tai-Chi- } \\
\text { Chuan) }\end{array}$ & $9,1 \%$ & $15,2 \%$ & $21,2 \%$ & $27,3 \%$ & $24,2 \%$ & $3 \%$ \\
\hline Microscada (Treinamento Contratual) & - & $12,5 \%$ & $21,9 \%$ & $25 \%$ & $31,3 \%$ & $9,4 \%$ \\
\hline
\end{tabular}

Nas análises estatísticas, utilizou-se o Teste $\mathrm{T}$ para verificar as diferenças entre as médias das variáveis Impacto de Treinamento no Trabalho e Suporte à Transferência, compreendendo duas variáveis independentes, Suporte Gerencial e Social à Transferência de Treinamento (fatores situacionais de apoio e conseqüências associadas ao uso das novas habilidades); e Suporte Material à Transferência, referentes a cada grupo de treinamento. Os resultados encontrados demonstraram existirem diferenças significativas entre as médias das variáveis nos dois grupos de treinamento com $t=2,780$ e nível de significância de $\mathrm{p}<0,01$ para a variável Impacto do Treinamento no Trabalho; $\mathrm{t}=3,470$ e $\mathrm{p}<0,01$ para a variável Suporte Gerencial e Social à Transferência e $\mathrm{t}=4,317 \mathrm{e} \mathrm{p}<0,001$ para a variável Suporte Material à Transferência. A Tabela 3 apresenta as médias e o desvio padrão de cada grupo de treinamento e a Tabela 4, os valores de te níveis de significância.

\section{Tabela 3: T-teste das Médias e Desvios Padrões por Grupo de Treinamento}

\begin{tabular}{lccccc}
\hline \multicolumn{1}{c|}{ VARIÁVEIS } & $\begin{array}{c}\text { GRUPO DE } \\
\text { TREINAMENTO }\end{array}$ & $\begin{array}{c}\text { NÚMERO DE } \\
\text { RESPONDENTES }\end{array}$ & MÉDIA & DESVIO PADRÃo \\
\hline $\begin{array}{l}\text { Impacto de } \\
\text { treinamento no }\end{array}$ & $\mathrm{A}$ & 197 & 4,02 & 0,64 \\
trabalho & $\mathrm{B}$ & 178 & 3,81 & 0,81 \\
$\begin{array}{l}\text { Suporte gerencial e } \\
\text { social à }\end{array}$ & $\mathrm{A}$ & 197 & 3,31 & 0,72 \\
transferência & $\mathrm{B}$ & 178 & 3,08 & 0,82 \\
$\begin{array}{l}\text { Suporte material à } \\
\text { transferência }\end{array}$ & $\mathrm{A}$ & 197 & 4,23 & 0,64 \\
\hline
\end{tabular}




\section{Tabela 4: T-teste de Igualdade das Médias dos Grupos de Treinamento}

\begin{tabular}{lc|c}
\hline \multicolumn{1}{c|}{ VARIÁVEIS } & T & NIVEL DE SIGNIFICÂNCIA \\
\hline Impacto de treinamento no trabalho & 2,780 & $\mathrm{p}=0,006<0,01$ \\
Suporte gerencial e social à transferência & 3,470 & $\mathrm{p}=0,001<0,01$ \\
Suporte material à transferência & 4,317 & $\mathrm{p}=0,0001<0,001$ \\
\hline
\end{tabular}

Pelos níveis de significância encontrados nas diferenças entre as variáveis Impacto de Treinamento no Trabalho, Suporte Gerencial e Social e Suporte Material à transferência e os grupos de treinamento A e B, conclui-se que são significativos para confirmar a hipótese dessa pesquisa. Observa-se que Suporte Gerencial e Social e Suporte Material têm nível de significância menor que o de impacto de treinamento no trabalho, demonstrando que o suporte organizacional à transferência é maior, quando os treinamentos são relevantes para a estratégia organizacional.

$\mathrm{Na}$ análise de regressão, utilizou-se o método de regressão padrão, tendo em vista que a pesquisa teve caráter exploratório e a amostra foi pequena. Foram considerados 356 casos válidos da amostra após a retirada dos outliers. Na primeira equação da regressão padrão foram utilizadas todas as variáveis independentes do estudo para investigar a relação de predição sobre a variável dependente Impacto do Treinamento no Trabalho. São elas: Suporte à Transferência, compreendendo duas variáveis independentes, Suporte Gerencial e Social à Transferência de Treinamento (fatores situacionais de apoio e conseqüências associadas ao uso das novas habilidades) e Suporte Material à Transferência de Treinamento; variáveis demográficas (idade, sexo, nível de escolaridade, cargo/função exercido atualmente na Eletronorte, tempo de serviço na Eletronorte) e a variável Grupos de Treinamento A e B. A variável lotação teve um número maior que $5 \%$ de valores omissos e foi retirada da análise. Nessa análise, o $\mathrm{R}^{2}$ ajustado encontrado foi de 0,37, com nível de significância $\mathrm{p}<0,0001$.

A variável Suporte Gerencial e Social à Transferência de Treinamento apresentou um nível de significância $\mathrm{p}<0,0001$, indicando que esta variável é a principal preditora de impacto de treinamento no trabalho na organização. Entre todas as variáveis antecedentes, suporte gerencial e social à transferência foi a maior preditora de impacto de treinamento no trabalho na avaliação dos treinados com $\mathrm{Sr}^{2}$ 0,53, com Beta de 0,58. O Beta desta variável indica que, quanto maior a percepção de Suporte Gerencial e Social pelos treinados, maior a percepção de Impacto do Treinamento no Trabalho. Entre as variáveis demográficas, foram significativas na predição de impacto de treinamento no trabalho, $\mathrm{p}<0,05$, escolaridade $\left(1^{\circ}\right.$ grau incompleto), com Beta negativo, e cargo (empregado de nível médio), com Beta positivo. Isso significa que para os empregados com escolaridade mais baixa a ocorrência do impacto do treinamento no trabalho é menor, enquanto para os empregados de nível médio é maior. A Tabela 5 apresenta as correlações entre as variáveis, os coeficientes de regressão nãopadronizados (B), a constante, os coeficientes de regressão padronizados (b), as correlações semiparciais $\left(\mathrm{Sr}^{2}\right)$, o $\mathrm{R}$, o $\mathrm{R}^{2}$ e o $\mathrm{R}^{2}$ ajustado. 


\section{Tabela 5: Primeira Regressão Padrão na Predição do Impacto do} Treinamento no Trabalho com Todas as Variáveis Independentes

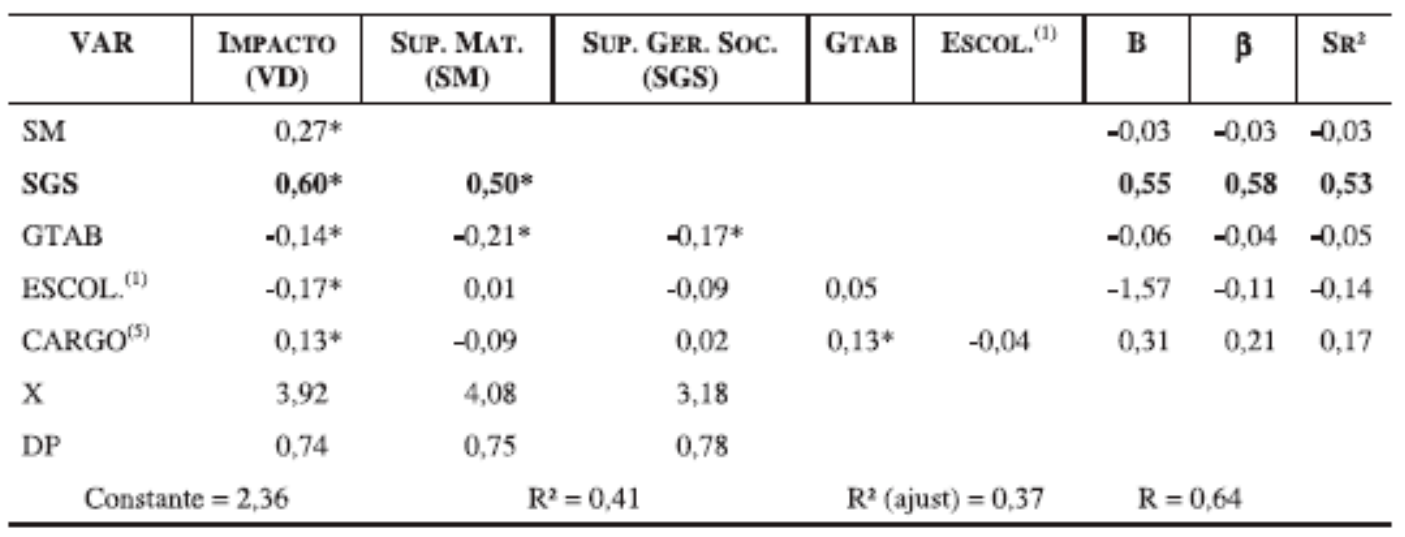

Nota: ${ }^{*} \mathrm{p}<=0,001$ (1) ESCOL. $=1^{\circ}$ Grau incompleto (5) CARGO = Empregado de nivel médio

A segunda análise de regressão padrão, tendo como variáveis independentes somente as variáveis demográficas e grupos de treinamento A e B, apresentou os seguintes resultados: $R^{2}$ ajustado de 0,06 com nível de significância $p<0,05$. As variáveis demográficas significativas foram escolaridade ( $1^{\circ}$ Grau incompleto) e ( $3^{\circ}$ Grau completo), ambas com Beta negativo, indicando que, para os empregados enquadrados nessas categorias, a percepção de impacto do treinamento no trabalho foi menor e cargo ocupado (empregado de nível médio), com Beta positivo, indicando que, para os empregados que ocupam esse cargo, houve maior percepção de impacto do treinamento no trabalho. Nessa análise, os grupos de treinamento A e B também foram significativos, com Beta negativo, indicando que os treinamentos do grupo A tem maior impacto. A Tabela 6 apresenta as correlações entre as variáveis, os coeficientes de regressão não-padronizados (B), a constante, os coeficientes de regressão padronizados (b), as correlações semiparciais $\left(\mathrm{Sr}^{2}\right)$, o $\mathrm{R}$, o $\mathrm{R}^{2}$ e o $\mathrm{R}^{2}$ ajustado.

Tabela 6: Segunda Regressão Padrão na Predição do Impacto do Treinamento no Trabalho com as Variáveis Demográficas e Grupos de Treinamento como Variáveis Independentes

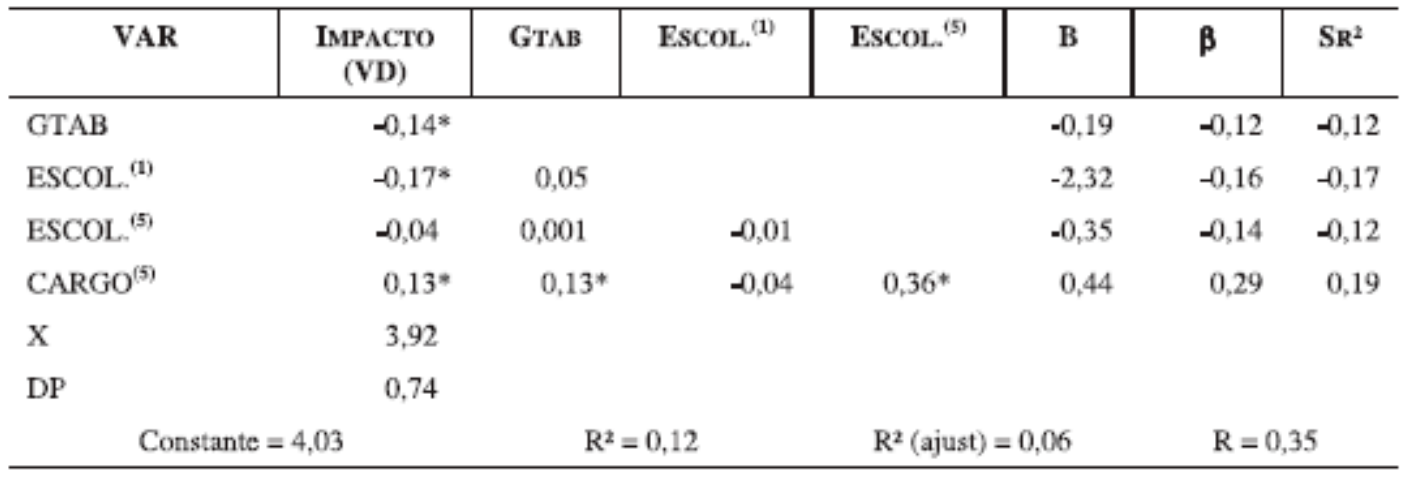

Nota: * $\mathrm{p}<=0,001$ (1) ESCOL. $=1^{\circ}$ Grau incompleto (5) ESCOL. $=3^{\circ}$ Grau completo (5) $\mathrm{CARGO}=$ Empregado de nível médio.

\section{4 - ANÁLISE CRÍTICA}

A pesquisa citada no estudo de caso não faz uma relação entre o Treinamento e o aumento de lucro da Organização, enfoca a Relevância do Treinamento como uma ferramenta que vai de encontro 
aos objetivos de crescimento da Organização, mas é possível afirmar que a lucratividade e a qualidade dos processos de uma empresa está diretamente ligada aos seus funcionários que por sua vez produzem cada vez mais se forem treinados para tal. "Toda empresa precisa se tornar uma instituição que aprende. Ela também precisa se tornar uma instituição de ensino". (DRUCKER, 2002)

Os resultados da pesquisa apontam uma possível interação do impacto do treinamento no trabalho do indivíduo com o impacto no nível organizacional. Além disso, acrescenta-se uma discussão teórica sobre as razões pelas quais os indivíduos transferem para o trabalho as habilidades adquiridas em treinamento, quando percebem a relevância do treinamento para a organização. A hipótese da pesquisa foi confirmada, dessa forma, pesquisas devem continuar investigando evidências que comprovem se os treinamentos tem impacto favorável no trabalho das pessoas. O impacto dos treinamentos foi maior para os funcionários com $1^{\circ}$ Grau Incompleto do que para os que eram nível médio completo, em média $4 \%$ a mais. Isso se dá pelo fato da empresa investir em seu patrimônio vivo. Para o físico e escritor Capra (1982) é preciso rever o conceito de trabalho e sua prática, de tal forma que passe a ser significativo e pleno para o trabalhador e útil para sociedade.

Um treinamento quando bem executado gera grandes diferenciais para o negócio e vantagem competitiva. Também é possível observar aumento dos níveis de qualidade, aumento de produtividade e por fim aumento da lucratividade.

\section{5 - CONSIDERAÇÕES FINAIS}

Observando as pesquisas feitas e o resultado do Estudo de caso relido, foi possível responder a pergunta feita no início desse Artigo. Qual a real importância do treinamento para o bom desempenho organizacional visando o lucro?

O treinamento é ferramenta fundamental para desenvolver as pessoas que fazem parte do quadro de funcionários da organização, o mercado exige que as empresas possuam pessoas aptas e preparadas para atuar de forma diferenciada, tornando-se competitiva no mercado de atuação.

O treinamento não pode ser confundido com a simples realização de cursos que transmitem novas informações. Treinar significa atingir o nível de desempenho desejado pela organização por meio do desenvolvimento contínuo dos indivíduos que nela trabalham e para isto é necessária uma cultura organizacional favorável ao aprendizado e comprometida com as mudanças.

Além disso, é preciso verificar se as técnicas de treinamento são eficazes no alcance dos objetivos propostos pela empresa. Pois, como dito no início deste, os Recursos Humanos são o patrimônio fundamental das organizações. 
Conclui-se desta maneira, que o funcionário que passa por um bom treinamento adquire novos hábitos, conhecimentos e habilidades no âmbito profissional, trazendo bons resultados para a empresa e por consequência aumentando seu lucro, levando em conta também que todo o investimento feito em seus colaboradores retorna e forma de crescimento individual e coletivo para a organização. Baseado nisso tão importante quanto investir em maquinário e modernidades, investir em pessoas passa a ser primordial para o aumento de lucro das organizações.

\section{REFERÊNCIAS BIBLIOGRÁFICAS}

BOHLANDER, George; SNELL, Scott. Administração de Recursos Humanos. São Paulo: Cengace Learning, 2009.

BOOG, Gustavo G (coord.). Manual de Treinamento e Desenvolvimento: um guia de operações manual oficial da ABTD. São Paulo: Makron Books, 2001.

CARVAlHO, A. V. Administração de Recursos Humanos. Volume 1. São Paulo: Pioneira, 1997.

CHIAVENATO, Idalberto. Introdução a teoria geral da Administração. São Paulo: Campus, 1999.

CONSULTORIA E SOLUÇÕES EM GESTÃO DE MANUTENÇÃO. Disponível em: csgm.com.br: Acessado em: 27/05/2016.

CRESWELL, John W. Investigação Qualitativa e Projeto de Pesquisa: escolhendo entre cinco abordagens. 3. ed. Porto Alegre. Penso, 2014. 341p.

CRESWELL, John W. Projeto de Pesquisa: Métodos Qualitativo, Quantitativo e Misto. 2a ed.,Porto Alegre: Artmed, 2007.

DRUCKER, Peter. Administração na próxima sociedade. Tradução de Nivaldo M. Jr. São Paulo: Nobel, 2002.

GARLAND, Ron. Administração e Gerenciamento para a nova era. $2^{\circ}$ edição. São Paulo: Saraiva, 1993.

RIBEIRO, A. L. Gestão de pessoas. São Paulo: Saraiva, 2006. 


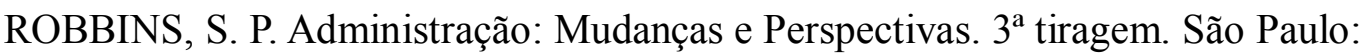

Saraiva, 2002(a); Comportamento Organizacional. $9^{\circ}$ edição. São Paulo: Prentice Hall, 2002(b).

SANTOS, Jeogen. RH e Segurança do trabalho. Disponível em: jeogensantos.blogspot.com.br. Acessado em: $30 / 06 / 2016$.

SILVA, M. E. Relações entre impacto do treinamento no trabalho e estratégia empresarial: o caso da Eletronorte, Artigo publicado em 2004. Disponível em: Google Acadêmico. Acessado em: 10/06/2016

TACHIZAWA, Takeshy; FERREIRA, Victor Cláudio Paradela; FORTUNA, Antônio Alfredo Mello. Gestão com Pessoas: uma abordagem aplicada às estratégias de negócios. $2^{\circ}$ edição. São Paulo: FGV, 2001.

Recebido em: 14/08/2016

Aceito em: 13/09/2016

Nome: Ana Cláudia Tavares da Silva Manhães

email: anaclaudia.manhaes@gmail.com

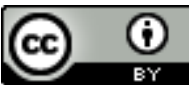

Este obra está licenciada com uma Licença Creative Commons Atribuição 4.0 Internacional. 